\title{
Proteomic profiling of bladder cancer for precision medicine in the clinical setting: A review for the busy urologist
}

\author{
Jayoung Kim ${ }^{1,2}$ (1), Peng Jin ${ }^{1,3}$ (1), Wei Yang ${ }^{1,2}$ (1), Wun-Jae Kim ${ }^{4,5}$ \\ ${ }^{\prime}$ Departments of Surgery and Biomedical Sciences, Cedars-Sinai Medical Center, Los Angeles, CA, ${ }^{2}$ Department of Medicine, University of California Los Angeles, Los \\ Angeles, CA, USA, ${ }^{3}$ Department of Urology, Shengjing Hospital of China Medical University, Shenyang, China, ${ }^{4}$ Department of Urology, Chungbuk National University \\ College of Medicine, Cheongju, Institute of UroTech, Cheongju, Korea
}

At present, proteomic methods have successfully identified potential biomarkers of urological malignancies, such as prostate cancer (PC), bladder cancer (BC), and renal cell carcinoma (RCC), reflecting different numbers of key cellular processes, including extracellular environment modification, invasion and metastasis, chemotaxis, differentiation, metabolite transport, and apoptosis. The potential application of proteomics in the detection of clinical markers of urological malignancies can help improve patient assessment through early cancer detection, prognosis, and treatment response prediction. A variety of proteomic studies have already been carried out to find prognostic BC biomarkers, and a large number of potential biomarkers have been reported. It is worth noting that proteomics research has not been applied to the study of predictive markers; this may be due to the incompatibility between the number of measured variables and the available sample size, which has become particularly evident in the study of therapeutic response. On the contrary, prognostic correlation is more common, which is also reflected in existing research. We are now entering an era of clinical proteomics. Driven by proteomic-based workflows, computing tools, and the applicability of cross-correlation of proteomic data, it is now feasible to use proteomic analysis to support personalized medicine. In this paper, we will summarize the current emerging technologies for advanced discovery, targeted proteomics, and proteomic applications in BC, particularly in discovery of human-based biomarkers.

Keywords: Precision medicine; Review; Urinary bladder neoplasms

This is an Open Access article distributed under the terms of the Creative Commons Attribution Non-Commercial License (http://creativecommons.org/licenses/by-nc/4.0) which permits unrestricted non-commercial use, distribution, and reproduction in any medium, provided the original work is properly cited.

\section{INTRODUCTION}

Bladder cancer (BC) is the fourth most common malignant tumor in the United States. Traditionally, based on the degree of invasion in the bladder muscle wall, $\mathrm{BC}$ can be classified into either non-muscle invasive (NMIBC) or muscle invasive (MIBC) [1] Based on the differing histology of $\mathrm{BC}$, there are several types. Transitional cell carcinoma (TCC) accounts for about $90 \%$ of all BC [2]. Other histological variants found in clinical specimens include squamous, glandular, plasmacytoid, sarcomatoid, micropapillary, and small cell carcinoma [3]. BC can also be divided pathologically into low-grade (LG) or high-grade (HG) tumors. LG tumors are usually well-differentiated, while HG tumors are poorly dif-

Received: 9 July, 2020 • Accepted: 6 August, 2020 • Published online: 27 October, 2020

Corresponding Author: Wun-Jae Kim (iD https://orcid.org/0000-0002-8060-8926

Department of Urology, Chungbuk National University College of Medicine, 1, Chungdae-ro, Seowon-Gu, Cheongju 28644, Korea

TEL: +82-43-269-6371, FAX: +82-43-269-6144, E-mail: wjkim@chungbuk.ac.kr 
Table 1. Widely accepted classifications of BC based on molecular phenotypes

\begin{tabular}{lllll}
\hline \multicolumn{1}{c}{ UNC } & MDA & Lund & TCGA & Broad \\
\hline Basal & Basal & UroA & Cluster I & Basal \\
Luminal & Luminal & UroB & Cluster II & Luminal \\
Claudin-low & P53-like & GU & Cluster III & Luminal immune \\
& & SCCL & Cluster IV & Immune undifferentiated \\
& & & \\
\end{tabular}

BC, bladder cancer; UNC, the University of North Carolina; MDA, MD Anderson Cancer Center; Lund, Lund University; TCGA, The Cancer Genome Atlas; Broad, Broad Institute of Massachusetts Institute of Technology and Harvard University; UroA, urobasal A; UroB, urobasal B; GU, genomically unstable; SCCL, squamous cell carcinoma like.

ferentiated [4].

\section{SUBTYPE CLASSIFICATION OF BLAD- DER CANCER}

Recent genome mRNA expression analysis demonstrated that $\mathrm{BC}$ can be classified into molecular subtypes. These different molecular subtypes of $\mathrm{BC}$ have distinct progression patterns, biological and clinical properties, and response to chemotherapies. There are currently five published classification methods; these include guidelines from the University of North Carolina (UNC), MD Anderson Cancer Center (MDA), The Cancer Genome Atlas (TCGA), Lund University (Lund), and Broad Institute of Massachusetts Institute of Technology and Harvard University (Broad) (Table 1).

The classifications by UNC define two molecular subtypes of HG BC, "luminal" and "basal", with molecular features reflecting different stages of urothelial differentiation [5]. Luminal BC expresses terminal urothelial differentiation markers, such as those seen in umbrella cells (uroplakin- $1 B$ [UPK1B], UPK2, UPK3A, and keratin-20 [KRT20]), whereas basal $\mathrm{BC}$ expresses high levels of genes that are typical in urothelial basal cells (keratin-14 [KRT14], KRT5, and $K R T 5 B)$. The UNC study created a gene signature, BASE47, that accurately discriminates intrinsic BC subtypes. Identified basal tumors had significantly decreased disease-specific and overall survival (OS). In addition, among the clinicopathological features available in from the Memorial Sloan Kettering Cancer Center dataset, only the subtypes identified by the BASE47 signature were found to be significant in disease-specific survival by univariate analysis.

Kardos et al. [6] reported the discovery of a claudin-low molecular subtype of high-grade $\mathrm{BC}$ that shares characteristics with the homonymous subtype of breast cancer. Although there has been much work done on the molecular phenotyping of $\mathrm{BC}$, the different emphases of different classification methods have made it difficult to consolidate a widely accepted classification method. As a result, the molec- ular phenotyping of $\mathrm{BC}$ remains to be further studied. The claudin-low subtype can be considered a subpopulation of the basal-like subtype (UNC classification system). Claudinlow $\mathrm{BC}$ tumors are rich in a variety of genetic characteristics, including increased mutation rates of retinoblastoma transcriptional corepressor 1 (RB1), E1A binding protein P300 (EP300), and nuclear receptor corepressor 1 (NCOR1), and have increased frequency of estimated glomerular filtration rate $(E G F R)$ amplification, decreased mutation rates of fibroblast growth factor receptor 3 (FGFR3), E74-like ETS transcription factor 3 (ELF3), and lysine demethylase $6 \mathrm{~A}$ (KDM6A), and decreased frequency of peroxisome proliferator activated receptor gamma (PPAR $\gamma)$ amplification. These characteristics define a molecular subtype of $\mathrm{BC}$ with distinct molecular features and an immunological profile that is theoretically primed for an immunotherapeutic response.

The classification system by MDA identified three molecular subtypes of MIBC: "basal", "luminal", and "P53-like" [7]. Basal MIBC was associated with shorter disease-specific and OS, presumably because these patients tend to have more invasive and metastatic disease at presentation. Transcription factor P63 plays a central role in controlling basal gene signatures and preliminary data suggests that EGFR, signal transducer and activator of transcription 3 (STAT3), nuclear factor kappa-light-chain-enhancer of activated B cells $(\mathrm{NF} \mathrm{B})$, and hypoxia-inducible factor 1-alpha (Hif-1 $\alpha)$ are also involved. Luminal MIBC displays active estrogen receptor/tripartite motif containing 24 (ER/TRIM24) pathway gene expression and was enriched for forkhead box $A 1$ (FOXA1), GATA binding protein 3 (GATA3), Erb-B2 receptor tyrosine kinase 2 (ERBB2), and Erb-B2 receptor tyrosine kinase 3 (ERBB3). Luminal MIBC contains active PPAR gene expression and activating FGFR3 mutations; therefore, PPAR $\gamma$ - and FGFR-3-targeted agents may be therapeutic in this subtype. Because luminal MIBC responds well to neoadjuvant chemotherapy (NAC), targeted therapies should be combined with conventional chemotherapy for maximum efficacy. The P53-like MIBC responded very poorly to NAC 
and was consistently resistant to frontline neoadjuvant cisplatin-based combination chemotherapy. Additionally, comparative analysis of matched gene expression profiles before and after chemotherapy revealed that all resistant tumors expressed the wild-type P53 gene expression signature. These results indicate that "P53-ness" may play a central role in $\mathrm{BC}$ chemoresistance.

The classification system by TCGA identified four clusters (clusters I-IV) by analyzing RNA-seq data from 129 tumors [8]. Cluster I (papillary-like) is enriched for in tumors with papillary morphology, FGFR3 mutations, FGFR3 copy number gain, and elevated FGFR3 expression. Cluster I samples also had significantly lower expression of $m i R-99 a, m i R$ 100, miR-145, and miR-125b. Tumors with FGFR3 alterations and those that share similar cluster I expression profiles may respond well to inhibitors of FGFR and its downstream targets. Clusters I and II express high levels of GATA3 and FOXA1. Markers of urothelial differentiation, such as uroplakins, epithelial marker E-cadherin, and members of miR200 miRNAs, are also highly expressed in clusters I and II. Clusters I and II express high human epidermal growth factor receptor 2 (HER2) levels and an elevated estrogen receptor beta signaling signature, which suggests potential utilization of hormone therapies, such as tamoxifen or raloxifene. Cluster III (basal/squamous-like) express characteristic epithelial lineage genes, including KRT14, KRT5, KRT6A, and EGFR. Many of the samples in cluster III express cytokeratins (KRT14 and KRT5). Integrated expression profiling analysis of cluster III revealed an urothelial carcinoma subtype with cancer stem-cell expression features, perhaps providing another avenue for therapeutic targeting.

The Lund classification system defines five major urothelial carcinoma subtypes: urobasal A, genomically unstable, urobasal B, squamous cell carcinoma-like (SCC-like), and infiltrated tumor class [9]. This was established using gene expression profiles from 308 tumor cases. These different molecular subtypes show significantly different prognoses.

Urobasal A had the best prognosis, whereas urobasal B and SCC-like had the worst. The prognoses of the genomically unstable and infiltrated classes were found to be moderate. Urobasal A tumors were characterized by elevated expression of FGFR3, cyclin D1 (CCND1), P63 (TP63), as well as expression of KRT5 in cells at the tumor-stroma interface. The majority of urobasal A tumors were NMIBC and of low pathological grade. The genomically unstable subtype was characterized by expression of ERBB2 and cyclin E (CCNE), low expression of cytokeratins, and frequent mutations of P53 (TP53). Genomically unstable cases represented a highrisk group; as close to $40 \%$ were MIBC. This subtype also showed low phosphatase and tensin homolog (PTEN) expression. The SCC-like subtype was characterized by high expression of basal keratins, which are normally not expressed in the urothelium; these include KRT4, KRT6A, KRT6B, KRT6C, KRT14, and KRT16. SCC-like tumors also had markedly bad prognoses. Furthermore, this group showed a comparatively different proportion of female/male patients, reminiscent of the 1:1 proportion seen in patients diagnosed with bladder SCC, suggesting that females are more likely to develop urothelial carcinomas with a keratinized/squamous phenotype. Urobasal B tumors had several similarities to urobasal A tumors, such as a high FGFR3 mutation frequency, elevated FGFR3, CCND1, and TP63 levels, and expression of the FGFR3 gene signature. However, this group also showed frequent TP53 mutations and expression of several keratins specific for the SCC-like subtype. Additionally, $50 \%$ of the cases were MIBC, including 5 out of 9 that were FGFR3-mutated. The infiltrated subtype demonstrated a pronounced immunologic and extracellular membrane (ECM) signal, indicating the presence of immunologic and myofibroblast cells. This subtype most likely represents a heterogeneous class of tumors; immunohistochemistry (IHC) revealed the presence of tumors with genomically unstable, urobasal B, and SCC-like protein expression patterns in this group.

The Broad classification system defines four different subtypes: luminal, immune undifferentiated, luminal immune, and basal [10]. Approximately $41 \%$ of invasive BC cases were luminal, with high expression of KRT20 and $U P K_{S} 2 / 1 A / 1 B / 3 A$ as well as moderate to high expression of multiple pertinent transcription factors (Kruppel Like Factor 5 [KLF5], PPAR $\gamma$, and grainyhead-like 5 [GRHL5]). The luminal subtype was enriched for in male patients, $\mathrm{BC}$ with papillary histology, and stage II tumors. A third (29\%) of invasive $\mathrm{BC}$ was in the basal subtype, with high expression of $K R T 14, K R T 5, K R T 6 A / B$, and $K R T 16$, and low expression of uroplakins, which is consistent with basal or undifferentiated cytokeratin expression patterns. Consistent with prior studies, the basal subtype expressed TP63, TP73, MYC Proto-Oncogene, BHLH Transcription Factor (MYC), GFR, transglutaminase 1 (TGM1), and Sciellin (SCEL), which is indicative of some degree of squamous differentiation. The basal subtype was enriched for in female patients and tumors with nonpapillary histology. The basal subtype also expressed many immune genes at intermediate and somewhat variable levels. These genes include cytotoxic T-lymphocyte associated protein 4 (CTLA4) and CD274, which encodes for programmed death-ligand 1 (PD-L1), suggesting that there may be immune cell infiltration of tumors. A smaller per- 
centage of cancers (11\%) were grouped into a novel subtype called immune undifferentiated. These cancers showed very low expression of luminal markers, variable expression of basal cytokeratin, and relatively high expression of immune genes, including CTLA4 and CD274, which further suggests significant immune cell infiltration and possible immune evasion. Lastly, the luminal immune subtype group constitutes about $18 \%$ of all cases and is characterized by the expression of luminal genes (cytokeratins and uroplakins) and intermediate expression of immune genes. This group was notably enriched for in stage $\mathrm{N}+$ tumors. The luminal subtype was enriched for in cancers with FGFR3 mutations and amplification events involving PVRL4 (nectin-4) and tyrosine 3-monooxygenase/tryptophan 5-monooxygenase activation protein zeta ( $Y W H A Z$ ). The basal subtype was enriched for nuclear factor erythroid 2 like 2 (NFE2L2) mutations. Both the luminal immune and immune undifferentiated subtypes had high expression levels of zinc finger E-box binding homeobox 1 (ZEB1), ZEB2, and twist family BHLH transcription factor 1 (TWIST1), which is characteristic of epithelial-mesenchymal transition (EMT).

All classification systems discussed above are widely accepted and based on molecular phenotyping. With ongoing progress in $\mathrm{BC}$ research, additional phenotyping classifications have been proposed. Here, we want to introduce some of these new classification systems (Table 2).

Sjödahl et al. [11] proposed five major tumor-cell phenotypes in advanced BC: urothelial-like, genomically unstable (GU), basal/SCC-like, mesenchymal-like, and small-cell/ neuroendocrine-like. Urothelial-like tumors express FGFR3 and $C C N D 1$ and frequently demonstrate a loss of $9 p 21$ (cyclin dependent kinase inhibitor $2 A$ [CDKN2A]). GU tumors express forkhead box M1 (FOXM1), but not KRT5, and frequently show loss of $R B 1$. Basal/SCC-like tumors were found to express KRT5 and KRT14, but not FOXA1 and GATA3. The mesenchymal-like $\mathrm{BC}$ is a new subtype that shows a tumor-cell phenotype that starkly contrasts with previously defined subtypes and is biologically different from the basal/ SCC-like cases that they are clustered with. These tumor cells are mesenchymal-like and express typical mesenchymal genes, such as ZEB2 and vimentin (VIM). The consensus cluster, Sc/NE-like, harbors two very distinct tumor-cell phenotypes. Half of these tumors expressed markers that are typical for neuroendocrine differentiation. This part of the $\mathrm{Sc} / \mathrm{NE}$ consensus cluster also showed an absence of PPARG, FOXA1, uroplakin, KRT2O, and GATA3 expression.

Song et al. [12] explored large-scale genomic datasets encompassing NMIBC and MIBC, redefining four distinct molecular subtypes, aptly named classes $1-4$. Class 1 is characterized by decreased expression of genes involved in cell proliferation, signifying the less aggressive characteristics of class 1. Class 2 included both low-grade NMIBCs and a small number of MIBCs. Class 2 displayed downregulation of immune response pathways, such as antigen processing and presentation and $\mathrm{T}$ cell receptor signaling pathways. All verified human leukocyte antigen $(H L A)$ genes, which were associated with clinical prognosis in cancer patients [13] exhibited a specifically inhibited pattern in class 2 . They also examined activated functions in class 2 , observing increased expression of the oncogenes FGFR3 and $C C N D 1$ [3]. Class 3 exhibited similar involvement of high-grade NMIBC and MIBC. In particular, most T1 high-grade tumors (11 out of 16, 69\%) were classified into class 3 , indicating that class 3 might be capable of detecting high-risk NMIBC with progressive disease. Class 3 displayed activation of cell cycleassociated functions and the inhibition of genes involved in the Notch signaling pathway. These processes are associated with tumor progression [14-16]. Increased expression of cell cycle-related genes (E2F1, FOXM1, CCNB1, and CCNE1) [16-18] in class 3 was observed in both the NMIBC and MIBC cases. Finally, class 4, which contained the most MIBC cases, exhibited clear upregulation of genes implicated in extracellular matrix organization along with strong activation of immune response. Additionally, class 4 tumors exhibited overexpression of genes associated with EMT or myofibroblasts, which is a shared feature with the Lund infiltrated subtype [9].

Tan et al. [19] identified six molecular subtypes with differing OS and molecular features by analyzing 2,411 urothe-

Table 2. Recently developed new classifications of bladder cancer (BC) based on molecular phenotypes

\begin{tabular}{lclll}
\hline \multicolumn{1}{c}{ Sjödahl et al. [11] } & Song et al. [12] & \multicolumn{1}{c}{ Tan et al. [19] } & Robertson et al. [20] & Kamoun et al. [23] \\
\hline Urothelial-like & Class 1 & Neural-like & Luminal-papillary & Luminal papillary \\
Genomically unstable & Class 2 & HER2-like & Luminal-infiltrated & Luminal nonspecified \\
Basal/SCC-like & Class 3 & Papillary-like & Luminal & Luminal unstable \\
Mesenchymal-like & Class 4 & Luminal-like & Basal-squamous & Stroma-rich \\
Small-cell/neuroendocrine-like & & Mesenchymal-like & Neuronal & Basal/squamous \\
& & Squamous-cell carcinoma-like & & Neuroendocrine-like \\
\hline
\end{tabular}

SCC, squamous cell carcinoma; HER2, human epidermal growth factor receptor 2. 
lial BC tumors. These subtypes are neural-like, HER2-like, papillary-like, luminal-like, mesenchymal-like, and squamous cell carcinoma-like. The neural-like subtype (median OS, 87 mo) was prevalently MIBC and characterized by high WNT/ $\beta$-catenin signaling. HER2-like (median OS, $107.7 \mathrm{mo}$ ) evenly consisted of NMIBC and MIBC, with higher ERBB2 amplification and signaling. Papillary-like (median OS, >135 mo), an NMIBC subtype enriched in urothelial differentiation genes, showed a high frequency of actionable FGFR3 mutations, amplifications, and FGFR3-TACC3 fusion. Luminal-like (median OS, 91.7 mo), which was predominantly NMIBC, had higher mitogen-activated protein kinase (MAPK) signaling and more KRAS proto-oncogene, GTPase (KRAS), and lysine methyltransferase 2 C/D (KMT2 C/D) mutations than other subtypes. Mesenchymal-like (MES; median OS, $86.6 \mathrm{mo}$ ) and SCC-like (median OS, 20.6 mo) were predominantly MIBC. MES is high in AXL receptor tyrosine kinase (AXL) signaling, whereas SCC has elevated programmed death 1 (PD1), CTLA4 signaling, and macrophage M2 infiltration.

Robertson et al. [20] studied the mRNA expression of $\mathrm{BC}$ and identified five subtypes: luminal-papillary, luminalinfiltrated, luminal, basal-squamous, and neuronal. These subtypes were associated with OS. Luminal-papillary tumors had papillary shape, low stage, and high purity. It was characterized by FGFR3 mutations, fusion with Tacc3, and/or amplification. The risk of tumor progression and possibility of response to cisplatin-based NAC was very low [21]. The features of the luminal-infiltrated subtype included lowest purity, high expression of EMT, myofibroblast markers, and miR-200s, and moderate expression of CD274 and CTLA4. Simultaneously, this subtype was also characterized by wild type p53 [7]. These tumors were found to be possibly resistant to cisplatin. Several uroplakins (UPK1A, UPK2) and genes (krt20, snx31) had the highest gene expression levels in the luminal subtype tumors. The basal-squamous subtype was characterized by high expression of $C D 44, K R T 5, K R T 6 A$, KRT14, TGM1, DSC3, PI3, CD274, and CTLA4. The incidence rate of this tumor was high in females. Cisplatin-based NAC and immunological checkpoint therapy were both suitable treatments for this subtype [22]. The neuronal subtype was characterized by expression of both neuroendocrine and neuronal genes and elevated cell cycle signals reflective of proliferation status. Small cell neuroendocrine cancer was characterized by loss of TP53 and RB1. This subtype had the worst survival.

Kamoun et al. [23] identified six molecular subtypes of MIBC: luminal papillary, luminal non-specified, luminal unstable, stroma-rich, basal/squamous, and neuroendocrine-like. The three luminal subtypes were found to overexpress fea- tures of urothelial differentiation, such as PPARG/GATA3/ FOXA1. The characteristics of luminal papillary subtype included high expression of non-invasive TA pathway signal [24] and was closely related to FGFR3 transcription activity. Luminal papillary tumors were abundantly T2 or T3-4 tumors, and the proportion of patients under 60 years old was much higher. The luminal non-specified subtype displayed elevated stromal infiltration signatures, mainly fibroblastic. This was the only luminal subtype associated with immune infiltration signals, which were mainly for B and T lymphocytes. Luminal non-specified tumors were abundant in Elf3 gene mutations and was common in elderly patients. The luminal unstable subtype had higher cell cycle activity than other luminal tumors, and also contained frequent PPARG alterations and high-level amplification of E2F3 and SOX4. The stroma-rich subtype presented a moderate degree of urothelial differentiation. It is mainly manifested by stromal infiltration and overexpression of genes in smooth muscle, endothelial cells, fibroblasts, and myofibroblasts, and contains higher levels of non-tumor cells. Immune infiltration was mainly seen in stroma-rich tumors (mostly $\mathrm{T}$ cells and B cell markers). The basal/squamous subtype was characterized by overexpression of genes related to basal cell differentiation. Immune infiltration is also found in this subtype (mainly cytotoxic lymphocytes and natural killer cells) with high levels of nontumorous cells. Basal/squamous tumors were strongly related to STAT3 and EGFR regulon activity and HIF1A. Mutations in TP53 and RB1 were the most common in this subset of tumors. Basal/squamous tumors are more common in women, with a higher clinical stage and poorer prognosis. The neuroendocrine-like subtype was characterized by high expression of genes related to neuroendocrine differentiation. TP53 and RB1 inactivation was common, but no immune infiltration was detected in these tumors. Neuroendocrine-like tumor was the worst prognosis subtype.

\section{PROTEOME AND PROTEOMICS}

Proteins are effector molecules that mediate the functions of genes and their deregulation contributes to the pathogenesis and therapeutic resistance of many diseases, such as cancer and neurodegenerative disorders. They represent an enormously valuable resource for personalized diagnosis, prevention, monitoring, and treatment. Therefore, protein properties, such as abundance, post-translational modification, stability, localization, transportation, and interaction with other molecules, have been intensively studied. Historically, proteins were previously studied on an indi- 
Table 3. A summary of discovery and targeted proteomics technologies

\begin{tabular}{|c|c|c|c|c|c|}
\hline Category & Group & Quantification technology & $\begin{array}{c}\text { Typical protein } \\
\text { number }\end{array}$ & $\begin{array}{c}\text { Typical sample } \\
\text { size }\end{array}$ & $\begin{array}{c}\text { Emerging } \\
\text { technology }\end{array}$ \\
\hline \multirow[t]{4}{*}{ Discovery proteomics } & DDA-MS & Label-free (LFQ) & $1,000-15,000$ & $10 \mathrm{~s}$ & BoxCar \\
\hline & & Metabolic labeling (SILAC) & & & \\
\hline & & Chemical labeling (TMT) & & & \\
\hline & DIA-MS & Label-free (LFQ) & $1,000-5,000$ & $10 s-100 s$ & \\
\hline \multirow[t]{4}{*}{ Targeted proteomics } & MS-based & SRM/MRM & $10 \mathrm{~s}$ & $10 s-100 s$ & TOMAHAQ \\
\hline & & PRM & & & \\
\hline & MS-independent & Antibody-based (RPPA) & $100 \mathrm{~s}$ & $100 s-1,000 s$ & \\
\hline & & Aptmer-based (SOMAscan) & $1,000 \mathrm{~s}$ & $100 \mathrm{~s}-1,000 \mathrm{~s}$ & \\
\hline
\end{tabular}

DDA, data-dependent acquisition; MS, mass spectrometry; DIA, data-independent acquisition; LFQ, label-free quantification; SILAC, stable isotope labeling by amino acids in cell culture; TMT, tandem mass tag; SRM, selected reaction monitoring; MRM, multiple reaction monitoring; PRM, parallel reaction monitoring; RPPA, reverse-phase protein array.

vidual basis.

In the mid-90's, Wilkins et al. [25] coined the term "proteome" to describe the "PROTein complement of a genOME". Of note, proteomics is highly complementary to genomics and transcriptomics, which can only indirectly, and, often inconclusively, measure the aforementioned protein properties. Mainly owning to the rapid advancement of proteomics technologies, the past 25 years have witnessed an explosive growth of proteomics studies, reaching a staggering number of over 11,000 proteomics-related publications in PubMed in 2019, alone.

\section{THE PROTEOME IS A COMPLEX AND INFORMATION-RICH RESOURCE}

The human genome contains about 20,000 protein-coding genes. In comparison, the human proteome is much more complex and may contain over 6 million proteoforms (i.e., individual molecular forms of an expressed protein) [26]. The major sources of proteoform diversity include: (a) single-nucleotide polymorphisms and mutations at the DNA level, (b) alternative splicing and RNA editing at the RNA level, and (c) errors in translation and post-translational modifications (PTMs) at the protein level [27]. Among these, the biggest contributor of proteoform diversity is PTMs. Currently, over 200 PTMs, such as phosphorylation, ubiquitination, and glycosylation, have been characterized according to the UniProt database (https://www.uniprot.org/help/post-translational_ modification). Of note, PTMs are highly important for the regulation of protein function, activity, stability, localization, and interaction in both physiological and disease states.

\section{DISCOVERY AND TARGETED PRO- TEOMICS}

Proteomics can be broadly classified into discovery and targeted proteomics, which are highly complementary to each other. Discovery proteomics is generally used in hypothesis-free and comprehensive profiling studies to identify novel protein complexes as well as differentially expressed, modified, and/or localized proteins. It is a powerful tool for identifying novel candidate biomarkers and therapeutic targets and for providing fresh biological insights. In comparison, targeted proteomics is generally used to quantify candidate proteins of interest in a much larger cohort of samples with higher quantification accuracy and precision. Currently, a typical discovery proteomics study quantifies thousands of proteins in tens of samples, whereas a typical targeted proteomics study quantifies tens of proteins in hundreds of samples. A summary of the techniques for discovery and targeted proteomics is shown in Table 3.

Discovery proteomics is predominantly conducted using mass spectrometry (MS)-based technologies, which allows comprehensive analysis of protein abundance and PTMs without the required generation of target-specific antibodies [28]. Due to technical challenges, comprehensive analysis of intact proteins by MS (i.e., top-down proteomics) is still in its infancy. Hence, the vast majority of MS-based discovery proteomics studies are conducted using a bottom-up proteomics workflow, where proteins are extracted and digested into peptides by a sequence-specific enzyme (e.g, trypsin) prior to liquid chromatography-tandem mass spectrometry (LC-MS/ MS) analysis. The classical and preferred MS method for discovery proteomics is data-dependent acquisition (DDA), where a full spectrum of the peptides is acquired at the MS1 level, followed by the collection of as many fragmentation spectra at the MS2 level as possible, all of which is done in 
a cycle time of about 3 seconds. The newer and growing MS method for discovery proteomics is data-independent acquisition (DIA), where a mixture of peptides within a relatively wide window (e.g., $25 \mathrm{~m} / \mathrm{z}$ units at the MS1 level) is selected and fragmented, followed by the acquisition of fragments at the MS2 level.

For peptide/protein quantitation, DDA can be coupled with different quantification strategies such as label-free quantification (LFQ), stable isotope labeling by amino acids in cell culture (SILAC), and isobaric tag-based quantification, such as tandem mass tag (TMT), and isobaric tag for relative and absolute quantitation (iTRAQ) [29]. Of note, with the recent release of the TMTpro ${ }^{\mathrm{TM}}$ 16plex label reagents (Thermo Scientific, Waltham, MA, USA), up to 16 samples can be analyzed in a single analysis, offering highthroughput analytical capabilities. In comparison, DIA is almost exclusively coupled with LFQ, where samples have to be analyzed one by one. Nevertheless, for multi-batch sample analysis, the TMT method suffers from the "missing value" problem, which aggravates with increasing batch numbers. In comparison, the DIA method is less prone to the "missing value" issue and is thus more suitable for larger sample sizes. However, DIA suffers from limitations such as the requirement of pre-existing high-quality spectral libraries and the complexity of the resulting data [30].

Targeted proteomics can be performed using MS-based and MS-independent methods [31]. At present, the most widely used MS-based targeted proteomics methods include selected reaction monitoring (SRM) [32], also called multiple reaction monitoring (MRM), and parallel reaction monitoring (PRM) [33]. The most popular MS-independent targeted proteomics methods include antibody-based reverse-phase protein array (RPPA) [34] and more recently aptamer-based SOMAscan [35].

Both SRM and PRM assays monitor transitions, i.e., specific pairs of mass-to-charge $(\mathrm{m} / \mathrm{z})$ values associated with the peptide precursor and fragment ions, over elution time for specific, sensitive and precise quantification of peptides. SRM and PRM assays are typically conducted in triple quadrupole mass spectrometers (e.g, QTRAP) and high-resolution quadrupole-orbitrap mass spectrometers (e.g, Q Exactive), respectively. The major difference between SRM and PRM assays is that the former requires a predefined series of transitions, whereas the latter selects the best transitions in a post-acquisition step. Generally speaking, SRM offers higher sensitivity, whereas PRM provides higher specificity and is easier to set up.

The RPPA method was first introduced in 2001 [36] and has since become increasingly popular in targeted proteomic and phosphoproteomic analysis of small amounts of clinical specimens. RPPA contains hundreds of spots, of which each contains only one test sample. As such, each RPPA can contain hundreds of different samples in serial dilution. For protein quantification, an RPPA is probed with one single antibody that can be detected using fluorescent, colorimetric, or chemiluminescent assays. Therefore, the robustness, reproducibility, and sensitivity of the RPPA measurements are high. RPPA has been used to analyze 166 total proteins and 56 phosphoproteins across nearly 8,000 patient samples from 31 cancer types [37].

The SOMAScan assay relies on the distinctive proteinbinding properties of SOMAmer (slow off-rate modified aptamer) reagents, which consist of a short single-stranded DNA sequence with "protein-like" appendages that allow tight and specific binding to its protein target [38]. Recently, SOMAScan has been used measure about 5,000 proteins across nearly 17,000 participants with multiple different health states, demonstrating that protein expression patterns reliably encode for many health issues [35].

\section{EMERGING TECHNOLOGIES FOR AD- VANCED DISCOVERY AND TARGETED PROTEOMICS}

In the past few years, many exciting proteomics techniques were developed to improve the LC-MS dynamic range (e.g., BoxCar), speed of targeted proteomics (e.g., trigger by offset, multiplexed, accurate mass, high-resolution, absolute quantification, TOMAHAQ), ion resolving capability (e.g., ion mobility MS), sensitivity (e.g., single cell proteomics), and data analysis (e.g, machine learning for MS identification), to name a few [39]. To be more concise, we will only summarize the BoxCar and TOMAHAQ techniques.

\section{BoxCar extends the dynamic range by an order of magnitude}

The abundance of human proteins spans a large dynamic range: about 7 orders of magnitude in cells and up to 12 orders of magnitude in plasma [40]. In comparison, the typical dynamic range of detection for LC-MS is $4-6$ orders of magnitude [41]. Therefore, a fast and deep profiling of the proteome requires a significant improvement in the dynamic range of peptide sampling. Recently, the Mann group developed a novel data-acquisition method, termed BoxCar, which improves the quality of MS1 signals and the dynamic range by an order of magnitude [42]. BoxCar can be coupled with both DDA and DIA for improved proteomic profiling. However, similar to DIA-MS, BoxCar analysis also requires a 
pre-existing high-quality spectral library [42].

\section{TOMAHAQ increases the speed of targeted pro- teomics analysis by an order of magnitude}

SRM and PRM are predominantly coupled with labelfree analysis and, thus, lack multiplexing capabilities. Recently, a novel targeted proteomics method termed TOMAHAQ was developed by the Gygi group [43]. By combining sample multiplexing with targeted proteomics, TOMAHAQ increases the throughput by an order of magnitude, compared to SRM/PRM. Using TOMAHAQ, the Gygi group was able to accurately quantify 131 peptides at the speed of 90 cell lysate samples per day [43]. Nonetheless, TOMAHAQ analysis requires highly expensive tribrid mass spectrometers, limiting its widespread adoption in research and clinical applications.

\section{APPLYING PROTEOMICS TO BC RE- SEARCH}

\section{In vitro research}

Based on the hypothesis that urinary biomarkers of $\mathrm{BC}$ are secreted from tumors, proteomic methods have been applied in investigating the secretome of tumor cells. Lin et al. [44] investigated the secretome of malignant U1 and pre-malignant U4 BC cells. They identified some differences, including laminin alpha-5 chain, ADP-ribosylation factor guanine nucleotide-exchange factor 2 , and urokinasetype plasminogen activator (u-PA). Further studies on u-PA found that loss was associated with malignant transformation. Makridakis et al. [45] compared the secretome from T24 and aggressive T24M BC cells. Several proteins were identified as being associated with metastatic tumor transformation, including secreted protein acidic and cysteine rich (SPARC), tissue-type plasminogen activator (tPA), and clusterin. All of them were further validated by western blot analysis. Elevated SPARC levels in the urine of BC patients was found to be associated with tumor stage [46]. Additionally, the biological relevance of SPARC in BC was suggested when blocking SPARC with specific antibodies resulted in reduced cell motility in vitro.

\section{The clinical setting}

Given that patient response rates to the drugs reach only $25 \%$ efficiency in cancer, the demand for developing precision medicine is increasing [47]. It appears that there is no study demonstrating successful application of proteomics or other -omics technology in personalized medicine. However, as outlined in recently published review articles [48-50], sub- stantial progress has been made in identifying proteomicsderived BC biomarkers as well as putative targets for therapeutic intervention to support patient management (diagnosis, monitoring, stratification, and treatment). Urinary proteome profiling can be used to support diagnosis/ monitoring and stratification of personalized diseases; while tissue proteomics can address personalized therapeutic intervention by identifying new therapeutic targets.

\section{Diagnosis and monitoring of $\mathrm{BC}$}

Up to now, several urinary biomarkers have been described, including FDA-approved immunoassays, which detect the urinary levels of BC-associated antigen (BTA stat) and nuclear matrix protein 22 (NMP22) with moderate performance (NMP22: 68\% sensitivity, 79\% specificity [51]; BTA stat: $61 \%$ sensitivity, $78 \%$ specificity [52]). In addition, several single protein biomarkers have been thoroughly investigated, including matrix metalloproteinases (matrix metalloproteinase-9 and matrix metalloproteinase-10), angiogenic factors (plasminogen activator inhibitor 1, vascular endothelial growth factor, and angiogenin), apolipoproteins (apolipoprotein A-I, apolipoprotein A-II, and apolipoprotein E), interleukin-8, and carbonic anhydrase 9, all of which are usually assessed through immunoassays (ELISA) [49].

MRM has been used to validate previously reported biomarkers, including complement $\mathrm{C} 4$ gamma chain, apolipoprotein A-II precursor, ceruloplasmin, and prothrombin, in a set of $76 \mathrm{BC}$ patients and 23 disease-related controls (including patients with urinary tract infections and hematuria) [53]. Theodorescu et al. [54] found that fibrinopeptide was capable of detecting BC in healthy controls. Schiffer et al. [55] found that progesterone receptor membrane component 1 (PGRMC1), collagen type I alpha 1 chain (COL1A1), uromodulin (UMOD), and collagen type III alpha 1 chain (COL3A1) were capable of discriminating between muscle-invasive and NMIBC BC. Frantzi et al. [56] found that collagen fragments, hemoglobin subunit alpha (HBA), apolipoprotein A1 (APOA1), fibrinogen $\alpha$ (FIBA), $\beta$-2-microglobulin (B2M), and small proline-rich protein 3 (SPRR3), insulin (INS), histidinerich glycoprotein (HRG) could detect primary BC. Collagen fragments, APOA1, heparan sulfate proteoglycan 2 (HSPG2), ADAM metalpeptidase (ADAMTS1) with thrombolytic protein type 1 parent 1 , ADAM metalpeptidase domain 22 (ADAM22) was able to detect relapsed BC.

\section{Identification of novel drugs/drug targets}

Although there were initially no clear reports of potential drug targets from proteomic analysis of $\mathrm{BC}$, a study by Peng et al. [57] found that phosphoglycerate mutase 1 
(PGAM1) was significantly upregulated in BC compared to adjacent normal tissues. Using shRNA to silence PGAM1 reduced tumor growth and cell proliferation and increased apoptosis in vivo.

Several recent studies highlight the potential use of a tissue proteomics-based approach in identifying novel drug targets for BC. Using high-resolution LC-MS/MS, 144 proteins associated with $\mathrm{BC}$ invasion were identified [58], including multiple proteins previously associated with BC. These proteins include, but are not limited to, some annexins, alpha actinins, cathepsin E, hydroxyprostaglandin dehydrogenase 15-(NAD), thymidine phosphorylase, and others. Importantly, eukaryotic translation initiation factor 3 subunit D (EIF3D) was identified as a promising intervention target through computer analysis, and its functional correlation was investigated using in vitro and in vivo disease models. Specifically, it showed that stable knockdown of EIF3D using lentivirus-mediated RNA interference in a metastatic BC cell line (T24M) resulted in decreased cell proliferation, migration capacity, and colony formation. Subsequent studies in xenograft models showed reduced tumor growth.

$\mathrm{Xu}$ et al. [59] performed pull-down assays using recombinant progranulin and protein extracts from $5637 \mathrm{BC}$ cells. Proteomic analysis showed that the F-actin-binding protein, drebrin, was a novel progranulin-binding partner. Interestingly, it has been shown that drebrin depletion in tumorigenic BC cells inhibits motility, anchorage-independent growth, and tumor formation through the threonine kinase (AKT) and MAPK signaling pathways. This indicates that drebrin plays an important functional role in regulating progranulin action and may constitute a novel target for therapeutic intervention in BC. Chen et al. [60] particularly emphasized the potential significance of nucleophosmin (NPM), which is a protein associated with cell proliferation, migration, and anti-apoptotic effects in bladder carcinogenesis. NPM was ubiquitously expressed in all uroepithelial cell lines examined, suggesting its role in the development of human BC. Upregulation of NPM also seemed to be dose and time-dependent following treatment. Since soy isoflavones are capable of inhibiting NPM expression in vitro, soybean-based foods may potentially suppress NPM-related tumorigenesis.

Jiang et al. [61] confirmed that peroxiredoxin-I (Prx-I), which has rarely been previously linked directly to $\mathrm{BC}$, was significantly downregulated following BI-TK/GCV treatment. Silencing of Prx-I significantly inhibited growth, promoted apoptosis, and regulated the cell cycle in T24 BC cells. These findings give new insights into the treatment of $\mathrm{BC}$ and indicate Prx-I as a new therapeutic target.
Proteome analysis has been used to study the effects and molecular mechanisms of novel potential drugs for BC. Using the 5637 urinary BC cell line, Li et al. [62] evaluated the effect of five heat shock protein 90 (HSP90) inhibitors (AUY922, ganetespib, SNX2112, AT13387, and CUDC305) in vitro, followed by quantitative proteome analysis at the global and histone post-translational modification levels. HSP90 inhibitors suppress cell proliferation and growth in a dose and time-dependent manner. LC-MS/MS analysis identified 518 over two-fold upregulated and 811 more than two-fold downregulated proteins, which were commonly deregulated upon treatment with AUY922 and ganetespib. These include proteins involved in cell cycle regulation (several cyclins, cyclin-dependent kinases, cullin-1, and DNA replication licensing factor MCM 5 (minichromosome maintenance complex component 5), apoptosis (BAX, caspase-14, calpalin-7, and apoptosis inducing factor 1), DNA damage repair (DNA ligase 3 and DNA repair protein XRCC1 (X-ray repair cross complementing 1 ), as well as the generation of reactive oxygen species (glutathione peroxydases, glutathione S-transferases, and superoxide dismutase).

\section{HUMAN SPECIMENS-BASED PRO- TEOMICS BIOMARKERS}

\section{Identification of proteomic markers in human urine}

In hematuria patients, aurora A kinase (AURKA) can distinguish low-grade $\mathrm{BC}$ patients from normal healthy subjects [63]. After adjusting for patients, clinical characteristics, and treatment with Bacillus Calmette-Guerin, activated leukocyte cell adhesion molecule (ALCAM) was positively correlated with tumor stage and OS [64]. Nicotinamide Nmethyltransferase was elevated in $\mathrm{BC}$ patients and was correlated with histological grade [65]. Levels of apurinic/ apyrimidinic endonuclease 1/redox factor-1 (APE/Ref-1) was also elevated in $\mathrm{BC}$ compared to normal controls and was correlated with grade and stage. Additionally, APE/Ref-1 has been shown to be significantly increased in patients with a history of $\mathrm{BC}$ recurrence [66]. The urinary cytokeratin-20 (CK20) RT-PCR assay showed that the sensitivity of urothelial $\mathrm{BC}$ detection was $78 \%$ to $87 \%$, the specificity was $56 \%$ to $80 \%$, and the diagnostic accuracy improved with tumor progression [67]. However, its performance in low-grade tumors was relatively poor. Measurements of the urinary levels of CK8 and CK18 using the UBC Rapid Test were shown to be greater in high-grade $\mathrm{BC}$ than in low-grade $\mathrm{BC}$ [68].

There are a variety of markers that can potentially be used for BC detection. Elevated urinary levels of apolipo- 
proteins A1, A2, B, C2, C3, and E (APOA1, APOA2, APOB, $\mathrm{APOC} 2, \mathrm{APOC} 3$, and $\mathrm{APOE}$ ) were found in $\mathrm{BC}$ compared to healthy controls [53,69]. A study showed that urinary fragments of uromodulin, collagen $\alpha-1$ (I), collagen $\alpha-1$ (III), and membrane-associated progesterone receptor component 1 could distinguish MIBC from NMIBC [55]. Other panels used LL-8, MMP-9/10, angiogenin (ANG), APOE, SDC-1, $\alpha 1 \mathrm{AT}$, PAI1, VEGFA, and CA9 to identify BC in urine samples. The advantage of these multi-urinary protein biomarkers is evident in high and low-grade diseases [70]. Some urine markers, including midkine (MDK), synuclein G, CEA cell adhesion molecule 1 (CEACAM1), zinc-alpha-2-glycoprotein (ZAG2) [71], clusterin (CLU), and ANG, showed improved sensitivity and specificity in diagnosing NMIBC when used in immunoassays and urine cytology [72]. Levels of CK20 and insulinlike growth factor II (IGF-II) were increased in the urine sediments of NMIBC patients compared to controls [73]. Increased urinary levels of HAI-1 and epithelial cell adhesion molecule (EpCAM) are prognostic biomarkers of high-risk in NMIBC patients [74]. Urinary survivin has been shown to be a potential biomarker for $\mathrm{BC}$, and was further related to tumor stage, lymph node metastasis, and distant metastasis [75]. Overexpression of urinary levels of SNAIL were shown to be an independent prognostic factor for tumor recurrence in NMIBC [76]. Urinary CD44 was elevated in high-grade MIBC based on glycan-affinity glycoproteomics nanoplatforms [77].

\section{Identification of proteomic markers in tissue samples}

Several studies have reported that the results of urine analysis using proteomics can be further verified at the tissue level. Using two-dimensional electrophoresis (2DE), Peng et al. [57] found that PGAM1 was significantly upregulated in $\mathrm{BC}$ compared to adjacent tissue. In a parallel approach, cystatin B was found to be a prognostic biomarker at the tissue level; increased expression levels of the protein were correlated with stage, grade, recurrence, and progression [78].

Barboro et al. [79] studied invasive BC tissue to identify prognostic biomarkers. Using $2 \mathrm{DE}$, they found significant upregulation of lamin $\mathrm{B} 1$ and fibrinogen beta chain and reduction of actin, desmin and VIM in MIBC tissue specimens compared to normal and non-tumor sections. They also found that protein p54 was correlated with vascular invasion and survival. Moreira et al. [80] studied the prognostic value of BC-associated protein (BLCAP) in 2,108 BC tissue specimens from archival datasets. According to the protein expression levels and cell localization, cancer cells could be divided into 4 categories, and decreased staining intensity of BLCAP was correlated with tumor grade $(p<0.0001)$ and stage $(p<0.0001)$. Orenes-Piñero et al. [81] used protein arrays to identify serum proteins that were associated with BC. Two identified candidate biomarkers, dynamin and clusterin, were further evaluated using IHC in tissue arrays. Reduced levels of CLU was found to be associated with MIBC, while reduced dynamin was associated with adverse outcomes. Chung et al. [82] identified 12 proteins including cofilin that were differentially expressed in MIBC, compared to NMIBC.

Grau et al. [83] performed comparative proteomics on the human T24 BC cell line and its aggressive derivate, T24T. They identified cullin-3 (Cul3), a protein involved in ubiquitination, as being overexpressed in T24T cells. Silencing of this protein reduced proliferation and migration of $\mathrm{T} 24 \mathrm{~T}$. Along the same lines, the IHC expression levels of Cul3 in tissue microarrays were associated with tumor stage, metastasis, and disease-specific survival. Srinivasan et al. [84] used antibody microarrays to identify proteins that were differentially expressed between patients with and without local recurrence. They identified 255 proteins and found that prelamin-A/C (LMNA), transcription factor AP-1 (JUN), and nuclease-sensitive element-binding protein 1 (YBOX1) were significantly upregulated; whereas L-selectin (LYAM1), cyclin-dependent kinase inhibitor 1 (CDN1A), and mothers against decapentaplegic homolog 3 (SMAD3) were significantly downregulated. Hemdan et al. [85] studied stathmin 1 in the context of $\mathrm{BC}$ and found that increased expression in tissue was associated with adverse outcomes. Decreased expression of stathmin 1 reduced growth and migration of T24 cells. Chen et al. [86] used laser microdissection to compare the proteome of $\mathrm{BC}$ and adjacent non-tumorous tissue. The levels of 4F2 cell-surface antigen heavy chain (SLC3A2), stathmin (STMN1), and transgelin-2 (TAGLN2) were elevated in cancer cells. STMN1 and TAGLN2 were both found to be significantly increased in the urine of $\mathrm{BC}$ patients. $\mathrm{Wu}$ et al. [87] used IHC to identify the association of galectin-1 overexpression (previously identified by the group) with $\mathrm{BC}$ pathology and prognosis in a set of 185 primary cases. Increased expression of galectin-1 was significantly associated with tumor grade, vascular invasion, nodal status, and significantly predicted disease specific survival.

\section{Identification of proteomic markers in blood samples}

Compared to urinalysis, there are relatively few studies on blood-based BC proteomics. Bansal et al. [88] examined the serum of patients with low-grade and high-grade $\mathrm{BC}$ and healthy controls; they found that there were differences in the expression of five proteins, among which S100 calcium 
binding protein A8 (S100A8) and S100A9 could distinguish low-grade and high-grade BC. The authors further confirmed the findings in a later study by analyzing serum samples from 108 patients with $\mathrm{BC}$ ( 55 before and 53 after surgery) and 52 healthy patients. They found that the expression of S100A8, S100A9, S100A4 and carbonic anhydrase-1 (CA-1) decreased in $\mathrm{BC}$, and the expression of annexin $\mathrm{V}$ increased significantly after surgery compared to patients before [89].

Lemańska-Perek et al. [90] analyzed BC plasma samples and found three groups of proteins with different expression levels compared with normal samples. The first group were proteins that should not exist in normal plasma, including fibrinogen $\gamma$, plasma transferrin, and C3b. The second group of proteins had high expression in cancer plasma, including vitamin $\mathrm{D}$ binding protein, $\alpha$-2-macroglobulin, pigment epithelium derived factor, and binding globin. The third group of proteins had low expression in cancer plasma, including three molecular forms of immunoglobulin M (IgM).

\section{Identification of proteomic markers in saliva samples}

Like serum, saliva is a complex mixture of proteins with concentrations in excess of 10 orders of magnitude. The process of getting saliva is the least invasive and simplest. The saliva proteome is constantly changing from birth to adolescence, so age must be considered in the reference data [91]. At present, the study of salivary proteomics is mainly focused on oral diseases, such as oral cancer. There are also several reports about the relationship between salivary proteomics and gastric, breast, and lung cancers. However, there are no reports on salivary proteomics in BC. Therefore, the potential of proteomic $\mathrm{BC}$ markers in saliva samples remains to be confirmed.

Proteomics markers identified in different human samples are summarized in Table 4 [53,55,57,63-90].

\section{DIAGNOSTIC AND PROGNOSTIC VAL- UES OF PROTEOMIC MARKERS IN BC}

Many potential biomarkers from proteomic analysis have been reported, suggesting that proteomics can identify new biomarkers for diagnosis and prognosis. There are some FDA-approved immunoassays for diagnosing BC, including BTA stat and NMP22 [52]. Proteomic biomarkers can assist in stratifying patient prognoses in BC. There has been initial data indicating the substantial value of proteomic biomarkers and supporting the idea of using proteomics for patient stratification. In a study by Frantzi et al. [56], CE-MS urinary profiling data was able to reflect disease progression in
MIBC, which was indicated by the gradual changes in the abundance of the urinary peptides and cancer progression. Preliminary results support the use of urinary peptide profiling as a tool for stratifying non-invasive patients.

In addition, proteomics can evaluate the biological process behind $\mathrm{BC}$, determine the molecular subtype of $\mathrm{BC}$, improve our understanding of $\mathrm{BC}$ classification and prognosis, and improve the diagnosis and treatment of patients. de Velasco et al. [92] found two different molecular groups for $\mathrm{BC}$ using proteomic data; each of which have different functional characteristics and may provide new insight for the treatment of BC. In addition, they also defined a six-protein signature that can predict the prognosis of patients with MIBC and identified a functional node that can provide prognostic information, which provides a further means of evaluating $\mathrm{BC}$.

\section{CONCLUSIONS}

Recent genomic studies to phenotype $\mathrm{BC}$ suggest that molecular subtypes of $\mathrm{BC}$ and their phenotypes can predict clinical outcomes to various therapies. However, recent findings also suggest that clinical parameters outperformed subtypes for predicting patient outcomes [93], and molecular subtype-based diagnostics applied to a population-based modern cystectomy series were not able to predict cancer-specific survival [94]. Thus, it would be worthy to consider the rapid advancement of existing and emerging proteomics technologies to molecular classification based on genomics phenotypes.

Proteomics is expected to improve personalized medical treatment by better assessing disease risk, more accurately monitoring disease, and improving targeted treatment. Although it is still in its infancy, the past few years have witnessed the emergence of single-molecule proteomic technologies [95,96]. These unbiased protein sequencing approaches, with a dynamic range that covers the full range of protein concentrations in proteomes, can potentially revolutionize the proteomics field. The addition of proteomics profilingbased biosignatures will provide tremendous benefit to the existing molecular phenotyping of $\mathrm{BC}$ patients in deciding treatment protocols, monitoring responses to therapies and recurrence or screening of high-risk individuals.

For successful clinical application, prospective multicenter based randomized trials should be considered to develop and assess the value of combined genomic and proteomic biomarker tests with the purpose of reducing costly cystoscopy checks during surveillance of $\mathrm{BC}$ patients. We are very optimistic that the utility of proteomic phenotyping 
Table 4. Proteomics markers in different samples

\begin{tabular}{|c|c|c|c|c|}
\hline $\begin{array}{c}\text { Sample } \\
\text { source }\end{array}$ & Proteomics marker & Expression & Function & Literature \\
\hline \multirow[t]{17}{*}{ Urine } & AURKA & & $\begin{array}{l}\text { Distinguish between low-grade BC patients and normal } \\
\text { patients }\end{array}$ & de Martino et al. [63] \\
\hline & ALCAM & & Positively correlate with tumor stage and OS & Arnold Egloff et al. [64] \\
\hline & NNMT & Increase & Correlate with histological grade & Pozzi et al. [65] \\
\hline & APE/Ref-1 & Increase & Correlate with the grade and stage of $\mathrm{BC}$ & Choi et al. [66] \\
\hline & CK20 & & Improve diagnostic accuracy in tumor progression & Mi et al. [67] \\
\hline & CK8 and CK18 & Increase & Differentiate between high-level and low-level BC & Ecke et al. [68] \\
\hline & $\begin{array}{l}\text { APOA1, APOA2, APOB, APOC2, APOC3, } \\
\text { APOE }\end{array}$ & Increase & $\mathrm{BC}$ detection & Chen et al. $[53,69]$ \\
\hline & $\begin{array}{l}\text { Uromodulin, collagen } \alpha-1 \text { (I), } \\
\text { collagen } \alpha-1 \text { (III), mPR }\end{array}$ & & Distinguish MIBC from NMIBC51 & Schiffer et al. [55] \\
\hline & $\begin{array}{l}\text { IL-8, MMP-9/10, ANG, APOE, SDC-1, } \\
\alpha 1 \text { AT, PAI-1, VEGFA, CA9 }\end{array}$ & & $\mathrm{BC}$ detection & Masuda et al. [70] \\
\hline & MDK, synuclein G, CEACAM1, ZAG2 & & NMIBC detection & Soukup et al. [71] \\
\hline & $\mathrm{CLU}$ and $\mathrm{ANG}$ & & NMIBC detection & Shabayek et al. [72] \\
\hline & CK20 and IGF-II & Increase & NMIBC detection & Salomo et al. [73] \\
\hline & HAI- 1 and EpCAM & Increase & NMIBC prognosis detection & Snell et al. [74] \\
\hline & Survivin & & $\begin{array}{l}\text { Relate to tumor stage, lymph node metastasis, and distant } \\
\text { metastasis }\end{array}$ & Yang et al. [75] \\
\hline & Snail & Increase & Prognostic factor for tumor recurrence in NMIBC & Santi et al. [76] \\
\hline & CD44 & Increase & High-grade MIBC detection & Azevedo et al. [77] \\
\hline & STMN1 and TAGLN2 & Increase & $\mathrm{BC}$ detection & Chen et al. [86] \\
\hline \multirow[t]{14}{*}{ Tissue } & PGAM1 & Increase & $\mathrm{BC}$ detection & Peng et al. [57] \\
\hline & Cystatin B & Increase & $\begin{array}{l}\text { Correlated with stage and grade, recurrence and progres- } \\
\text { sion }\end{array}$ & Feldman et al. [78] \\
\hline & Lamin B1 and fibrinogen beta chain & Increase & Identify prognostic & Barboro et al. [79] \\
\hline & Actin, desmin and vimentin & Decrease & Identify prognostic & Barboro et al. [79] \\
\hline & p54 & & Correlate with vascular invasion and survival & Barboro et al. [79] \\
\hline & BLCAP & Decrease & Correlate with tumor grade and stage & Moreira et al. [80] \\
\hline & Clusterin & Decrease & Associate with muscle invasive bladder cancer & Orenes-Piñero et al. [81] \\
\hline & Dynamin & Decrease & Associated with adverse outcomes & Orenes-Piñero et al. [81] \\
\hline & Cofilin & Increase & $\mathrm{BC}$ detection & Chung et al. [82] \\
\hline & Cul3 & Increase & $\begin{array}{l}\text { Associate with tumor stage, metastasis and } \\
\text { disease-specific survival }\end{array}$ & Grau et al. [83] \\
\hline & LMNA, JUN, YBOX1 & Decrease & Identify local recurrence & Srinivasan et al. [84] \\
\hline & Stathmin 1 & Increase & Associate with adverse outcomes & Hemdan et al. [85] \\
\hline & SLC3A2, STMN1 and TAGLN2 & Increase & $\mathrm{BC}$ detection & Chen et al. [86] \\
\hline & Galectin-1 & Increase & $\begin{array}{l}\text { Associate with tumor grade, vascular invasion, nodal sta- } \\
\text { tus, and significantly predicted disease specific survival }\end{array}$ & Wu et al. [87] \\
\hline \multirow[t]{4}{*}{ Blood } & $\begin{array}{l}\text { S100A8, S100A9, S100A4, CA-1 and an- } \\
\text { nexin V }\end{array}$ & Decrease & $\begin{array}{l}\text { Distinguish low-grade and high-grade bladder cancer from } \\
\text { healthy people }\end{array}$ & Bansal et al. [88,89] \\
\hline & Fibrinogen $\gamma$, plasma transferrin and C3b & $\begin{array}{c}\text { Not exist in } \\
\text { normal } \\
\text { plasma }\end{array}$ & $\mathrm{BC}$ detection & Lemańska-Perek et al. [90] \\
\hline & $\mathrm{DBP}, \alpha 2 \mathrm{M}, \mathrm{PEDF}$ and binding globin & Increase & $\mathrm{BC}$ detection & Lemańska-Perek et al. [90] \\
\hline & Three molecular forms of IgM & Decrease & $\mathrm{BC}$ detection & Lemańska-Perek et al. [90] \\
\hline
\end{tabular}

$\alpha 1$ AT, alpha-1-antitrypsin; $\alpha 2 \mathrm{M}, \alpha 2$-macroglobulin; ALCAM, activated leukocyte cell adhesion molecule; ANG, angiogenin; APO, apolipoproteins; APR/ReF-1, apurinic/apyrimidinic endonuclease 1/redox effector factor-1; AURKA, aurora A kinase; BLCAP, BC-associated protein; CA, carbonic anhydrase; CEACAM1, CEA cell adhesion molecule 1; CK, cytokeratin; CLU, clusterin; Cul3, cullin-3; DBP, vitamin D binding protein; EpCAM, epithelial cell adhesion molecule; HAI-1, hepatocyte growth factor activator inhibitor type 1; IGF-II, insulin-like growth factor II; IgM, immunoglobulin M; IL, interleukin; JUN, transcription factor AP-1; LMNA, prelamin-A/C; MDK, midkine; MMP, matrix metalloproteinases; mPR, membrane progesterone receptors; NNMT, nicotinamide N-methyltransferase; PAI-1, plasminogen activator inhibitor-1; PEDF, pigment epithelium-derived factor; PGAM1, phosphoglycerate mutase 1; S100A, S100 calcium binding protein A; SDC-1, syndecan 1; SLC3A2, 4F2 cell-surface antigen heavy chain; STMN1, stathmin 1; TAGLN2, transgelin-2; VEGFA, vascular endothelial growth factor A; YBOX1, nuclease-sensitive element-binding protein 1; ZAG2, Zincalpha-2-glycoprotein. 
combined with genomic phenotyping will play an increasingly important role in research and clinical management in conjunction with standard diagnostic procedures and act as an additional supplement to clinical judgment.

\section{CONFLICTS OF INTEREST}

The authors have nothing to disclose.

\section{ACKNOWLEDGMENTS}

This research was supported by Osong Medical Innovation foundation funded by Chungcheongbuk-do (AG200902001). The authors acknowledge support from National Institutes of Health grants (1U01DK103260, 1R01DK100974, U24 DK097154, NIH NCATS UCLA CTSI UL1TR000124), Department of Defense grants (W81XWH-15-1-0415 and W81XWH-19-1-0109), Centers for Disease Controls and Prevention (1U01DP006079), and the U.S.Egypt Science and Technology Joint Fund (to J.K.). In addition, this article is derived from the Subject Data funded in whole or part by National Academies of Sciences, Engineering, and Medicine (NAS) and The United States Agency for International Development (USAID). Any opinions, findings, conclusions, or recommendations expressed in this article are those of the authors alone, and do not necessarily reflect the views of USAID or NAS.

\section{AUTHORS' CONTRIBUTIONS}

Research conception and design: Jayoung Kim and WunJae Kim. Data acquisition: Peng Jin and Wei Yang. Data analysis and interpretation: Peng Jin and Wei Yang. Drafting of the manuscript: Peng Jin and Wei Yang. Critical revision of the manuscript: Jayoung Kim. Supervision: Jayoung Kim and Wun-Jae Kim. Approval of the final manuscript: all authors.

\section{REFERENCES}

1. Moch H, Cubilla AL, Humphrey PA, Reuter VE, Ulbright TM. The 2016 WHO classification of tumours of the urinary system and male genital organs-part A: renal, penile, and testicular tumours. Eur Urol 2016;70:93-105.

2. Kirkali Z, Chan T, Manoharan M, Algaba F, Busch C, Cheng L, et al. Bladder cancer: epidemiology, staging and grading, and diagnosis. Urology 2005;66(6 Suppl 1):4-34.

3. Sanli O, Dobruch J, Knowles MA, Burger M, Alemozaffar M, Nielsen ME, et al. Bladder cancer. Nat Rev Dis Primers
2017;3:17022.

4. Reuter VE. The pathology of bladder cancer. Urology 2006;67(3 Suppl 1):11-7; discussion 17-8.

5. Damrauer JS, Hoadley KA, Chism DD, Fan C, Tiganelli CJ, Wobker SE, et al. Intrinsic subtypes of high-grade bladder cancer reflect the hallmarks of breast cancer biology. Proc Natl Acad Sci U S A 2014;111:3110-5.

6. Kardos J, Chai S, Mose LE, Selitsky SR, Krishnan B, Saito R, et al. Claudin-low bladder tumors are immune infiltrated and actively immune suppressed. JCI Insight 2016;1:e85902.

7. Choi W, Porten S, Kim S, Willis D, Plimack ER, Hoffman-Censits J, et al. Identification of distinct basal and luminal subtypes of muscle-invasive bladder cancer with different sensitivities to frontline chemotherapy. Cancer Cell 2014;25:152-65.

8. Cancer Genome Atlas Research Network. Comprehensive molecular characterization of urothelial bladder carcinoma. Nature 2014;507:315-22.

9. Sjödahl G, Lauss M, Lövgren K, Chebil G, Gudjonsson S, Veerla S, et al. A molecular taxonomy for urothelial carcinoma. Clin Cancer Res 2012;18:3377-86.

10. Kim J, Akbani R, Creighton CJ, Lerner SP, Weinstein JN, Getz $\mathrm{G}$, et al. Invasive bladder cancer: genomic insights and therapeutic promise. Clin Cancer Res 2015;21:4514-24.

11. Sjödahl G, Eriksson P, Liedberg F, Höglund M. Molecular classification of urothelial carcinoma: global mRNA classification versus tumour-cell phenotype classification. J Pathol 2017;242:113-25.

12. Song BN, Kim SK, Mun JY, Choi YD, Leem SH, Chu IS. Identification of an immunotherapy-responsive molecular subtype of bladder cancer. EBioMedicine 2019;50:238-45.

13. Hirohashi Y, Torigoe T, Mariya T, Kochin V, Saito T, Sato N. HLA class I as a predictor of clinical prognosis and CTL infiltration as a predictor of chemosensitivity in ovarian cancer. Oncoimmunology 2015;4:e1005507.

14. Nowell CS, Radtke F. Notch as a tumour suppressor. Nat Rev Cancer 2017;17:145-59.

15. Rampias T, Vgenopoulou P, Avgeris M, Polyzos A, Stravodimos K, Valavanis C, et al. A new tumor suppressor role for the Notch pathway in bladder cancer. Nat Med 2014;20:1199-205.

16. Song BN, Kim SK, Chu IS. Bioinformatic identification of prognostic signature defined by copy number alteration and expression of CCNE1 in non-muscle invasive bladder cancer. Exp Mol Med 2017;49:e282.

17. Lee JS, Leem SH, Lee SY, Kim SC, Park ES, Kim SB, et al. Expression signature of E2F1 and its associated genes predict superficial to invasive progression of bladder tumors. J Clin Oncol 2010;28:2660-7.

18. Kim SK, Roh YG, Park K, Kang TH, Kim WJ, Lee JS, et al. Expression signature defined by FOXM1-CCNB1 activation 
predicts disease recurrence in non-muscle-invasive bladder cancer. Clin Cancer Res 2014;20:3233-43.

19. Tan TZ, Rouanne M, Tan KT, Huang RY, Thiery JP. Molecular subtypes of urothelial bladder cancer: results from a metacohort analysis of 2411 tumors. Eur Urol 2019;75:423-32.

20. Robertson AG, Kim J, Al-Ahmadie H, Bellmunt J, Guo G, Cherniack $\mathrm{AD}$, et al. Comprehensive molecular characterization of muscle-invasive bladder cancer. Cell 2018;174:1033.

21. Seiler R, Ashab HAD, Erho N, van Rhijn BWG, Winters B, Douglas J, et al. Impact of molecular subtypes in muscle-invasive bladder cancer on predicting response and survival after neoadjuvant chemotherapy. Eur Urol 2017;72:544-54.

22. Sharma P, Callahan MK, Bono P, Kim J, Spiliopoulou P, Calvo E, et al. Nivolumab monotherapy in recurrent metastatic urothelial carcinoma (CheckMate 032): a multicentre, openlabel, two-stage, multi-arm, phase 1/2 trial. Lancet Oncol 2016;17:1590-8.

23. Kamoun A, de Reyniès A, Allory Y, Sjödahl G, Robertson AG, Seiler R, et al. A consensus molecular classification of muscleinvasive bladder cancer. Eur Urol 2020;77:420-33.

24. Biton A, Bernard-Pierrot I, Lou Y, Krucker C, Chapeaublanc E, Rubio-Pérez C, et al. Independent component analysis uncovers the landscape of the bladder tumor transcriptome and reveals insights into luminal and basal subtypes. Cell Rep 2014;9:1235-45.

25. Wilkins MR, Sanchez JC, Gooley AA, Appel RD, HumpherySmith I, Hochstrasser DF, et al. Progress with proteome projects: why all proteins expressed by a genome should be identified and how to do it. Biotechnol Genet Eng Rev 1996;13:1950.

26. Ponomarenko EA, Poverennaya EV, Ilgisonis EV, Pyatnitskiy MA, Kopylov AT, Zgoda VG, et al. The size of the human proteome: the width and depth. Int J Anal Chem 2016;2016:7436849.

27. Aebersold R, Agar JN, Amster IJ, Baker MS, Bertozzi CR, Boja ES, et al. How many human proteoforms are there? Nat Chem Biol 2018;14:206-14.

28. Aebersold R, Mann M. Mass-spectrometric exploration of proteome structure and function. Nature 2016;537:347-55.

29. Ankney JA, Muneer A, Chen X. Relative and absolute quantitation in mass spectrometry-based proteomics. Annu Rev Anal Chem (Palo Alto Calif) 2018;11:49-77.

30. Ludwig C, Gillet L, Rosenberger G, Amon S, Collins BC, Aebersold R. Data-independent acquisition-based SWATHMS for quantitative proteomics: a tutorial. Mol Syst Biol 2018;14:e8126.

31. Yang W, Freeman MR, Kyprianou N. Personalization of prostate cancer therapy through phosphoproteomics. Nat Rev Urol 2018;15:483-97.
32. Lange V, Picotti P, Domon B, Aebersold R. Selected reaction monitoring for quantitative proteomics: a tutorial. Mol Syst Biol 2008;4:222.

33. Peterson AC, Russell JD, Bailey DJ, Westphall MS, Coon JJ. Parallel reaction monitoring for high resolution and high mass accuracy quantitative, targeted proteomics. Mol Cell Proteomics 2012;11:1475-88.

34. Liotta LA, Espina V, Mehta AI, Calvert V, Rosenblatt K, Geho $\mathrm{D}$, et al. Protein microarrays: meeting analytical challenges for clinical applications. Cancer Cell 2003;3:317-25.

35. Williams SA, Kivimaki M, Langenberg C, Hingorani AD, Casas JP, Bouchard C, et al. Plasma protein patterns as comprehensive indicators of health. Nat Med 2019;25:1851-7.

36. Paweletz CP, Charboneau L, Bichsel VE, Simone NL, Chen T, Gillespie JW, et al. Reverse phase protein microarrays which capture disease progression show activation of pro-survival pathways at the cancer invasion front. Oncogene 2001;20:19819.

37. Zhang Y, Kwok-Shing Ng P, Kucherlapati M, Chen F, Liu Y, Tsang YH, et al. A pan-cancer proteogenomic atlas of PI3K/ AKT/mTOR pathway alterations. Cancer Cell 2017;31:820-32. e3.

38. Rohloff JC, Gelinas AD, Jarvis TC, Ochsner UA, Schneider DJ, Gold L, et al. Nucleic acid ligands with protein-like side chains: modified aptamers and their use as diagnostic and therapeutic agents. Mol Ther Nucleic Acids 2014;3:e201.

39. Yates JR 3rd. Recent technical advances in proteomics. F1000Res 2019;8:F1000 Faculty Rev-351.

40. Zubarev RA. The challenge of the proteome dynamic range and its implications for in-depth proteomics. Proteomics 2013;13:723-6.

41. Angel TE, Aryal UK, Hengel SM, Baker ES, Kelly RT, Robinson EW, et al. Mass spectrometry-based proteomics: existing capabilities and future directions. Chem Soc Rev 2012;41:3912-28.

42. Meier F, Geyer PE, Virreira Winter S, Cox J, Mann M. BoxCar acquisition method enables single-shot proteomics at a depth of 10,000 proteins in 100 minutes. Nat Methods 2018;15:440-8.

43. Erickson BK, Rose CM, Braun CR, Erickson AR, Knott J, McAlister GC, et al. A strategy to combine sample multiplexing with targeted proteomics assays for high-throughput protein signature characterization. Mol Cell 2017;65:361-70.

44. Lin CY, Tsui KH, Yu CC, Yeh CW, Chang PL, Yung BY. Searching cell-secreted proteomes for potential urinary bladder tumor markers. Proteomics 2006;6:4381-9.

45. Makridakis M, Roubelakis MG, Bitsika V, Dimuccio V, Samiotaki M, Kossida S, et al. Analysis of secreted proteins for the study of bladder cancer cell aggressiveness. J Proteome Res 2010;9:3243-59.

46. Critselis E, Rava M, Marquez M, Lygirou V, Chatzicharalam- 
bous D, Liapi P, et al. Diagnostic and prognostic performance of secreted protein acidic and rich in cysteine (SPARC) assay for detecting primary and recurrent urinary bladder cancer. Proteomics Clin Appl 2019;13:e1800148.

47. Spear BB, Heath-Chiozzi M, Huff J. Clinical application of pharmacogenetics. Trends Mol Med 2001;7:201-4.

48. Frantzi M, Latosinska A, Flühe L, Hupe MC, Critselis E, Kramer MW, et al. Developing proteomic biomarkers for bladder cancer: towards clinical application. Nat Rev Urol 2015;12:31730.

49. Frantzi M, Vlahou A. Ten years of proteomics in bladder cancer: progress and future directions. Bladder Cancer 2017;3:118.

50. D'Costa JJ, Goldsmith JC, Wilson JS, Bryan RT, Ward DG. A systematic review of the diagnostic and prognostic value of urinary protein biomarkers in urothelial bladder cancer. Bladder Cancer 2016;2:301-17.

51. Mowatt G, Zhu S, Kilonzo M, Boachie C, Fraser C, Griffiths TR, et al. Systematic review of the clinical effectiveness and cost-effectiveness of photodynamic diagnosis and urine biomarkers (FISH, ImmunoCyt, NMP22) and cytology for the detection and follow-up of bladder cancer. Health Technol Assess 2010;14:1-331, iii-iv.

52. Yafi FA, Brimo F, Steinberg J, Aprikian AG, Tanguay S, Kassouf W. Prospective analysis of sensitivity and specificity of urinary cytology and other urinary biomarkers for bladder cancer. Urol Oncol 2015;33:66.e25-31.

53. Chen YT, Chen HW, Domanski D, Smith DS, Liang KH, Wu $\mathrm{CC}$, et al. Multiplexed quantification of 63 proteins in human urine by multiple reaction monitoring-based mass spectrometry for discovery of potential bladder cancer biomarkers. J Proteomics 2012;75:3529-45.

54. Theodorescu D, Wittke S, Ross MM, Walden M, Conaway M, Just I, et al. Discovery and validation of new protein biomarkers for urothelial cancer: a prospective analysis. Lancet Oncol 2006;7:230-40.

55. Schiffer E, Vlahou A, Petrolekas A, Stravodimos K, Tauber R, Geschwend JE, et al. Prediction of muscle-invasive bladder cancer using urinary proteomics. Clin Cancer Res 2009;15:4935-43.

56. Frantzi M, van Kessel KE, Zwarthoff EC, Marquez M, Rava M, Malats N, et al. Development and validation of urine-based peptide biomarker panels for detecting bladder cancer in a multi-center study. Clin Cancer Res 2016;22:4077-86.

57. Peng XC, Gong FM, Chen Y, Qiu M, Cheng K, Tang J, et al. Proteomics identification of PGAM1 as a potential therapeutic target for urothelial bladder cancer. J Proteomics 2016;132:8592.

58. Latosinska A, Mokou M, Makridakis M, Mullen W, Zoidakis
J, Lygirou V, et al. Proteomics analysis of bladder cancer invasion: targeting EIF3D for therapeutic intervention. Oncotarget 2017;8:69435-55.

59. Xu SQ, Buraschi S, Morcavallo A, Genua M, Shirao T, Peiper $\mathrm{SC}$, et al. A novel role for drebrin in regulating progranulin bioactivity in bladder cancer. Oncotarget 2015;6:10825-39.

60. Chen SH, Wang YW, Hsu JL, Chang HY, Wang CY, Shen PT, et al. Nucleophosmin in the pathogenesis of arsenic-related bladder carcinogenesis revealed by quantitative proteomics. Toxicol Appl Pharmacol 2010;242:126-35.

61. Jiang L, Xiao X, Ren J, Tang Y, Weng H, Yang Q, et al. Proteomic analysis of bladder cancer indicates Prx-I as a key molecule in BI-TK/GCV treatment system. PLoS One 2014;9:e98764.

62. Li QQ, Hao JJ, Zhang Z, Krane LS, Hammerich KH, Sanford $\mathrm{T}$, et al. Proteomic analysis of proteome and histone posttranslational modifications in heat shock protein 90 inhibitionmediated bladder cancer therapeutics. Sci Rep 2017;7:201.

63. de Martino M, Shariat SF, Hofbauer SL, Lucca I, Taus C, Wiener HG, et al. Aurora A Kinase as a diagnostic urinary marker for urothelial bladder cancer. World J Urol 2015;33:105-10.

64. Arnold Egloff SA, Du L, Loomans HA, Starchenko A, Su PF, Ketova T, et al. Shed urinary ALCAM is an independent prognostic biomarker of three-year overall survival after cystectomy in patients with bladder cancer. Oncotarget 2017;8:722-41.

65. Pozzi V, Di Ruscio G, Sartini D, Campagna R, Seta R, Fulvi P, et al. Clinical performance and utility of a NNMT-based urine test for bladder cancer. Int J Biol Markers 2018;33:94-101.

66. Choi S, Shin JH, Lee YR, Joo HK, Song KH, Na YG, et al. Urinary APE1/Ref-1: a potential bladder cancer biomarker. Dis Markers 2016;2016:7276502.

67. Mi Y, Zhao Y, Shi F, Zhang M, Wang C, Liu X. Diagnostic accuracy of urine cytokeratin 20 for bladder cancer: a metaanalysis. Asia Pac J Clin Oncol 2019;15:e11-9.

68. Ecke TH, Weiß S, Stephan C, Hallmann S, Barski D, Otto T, et al. UBC ${ }^{\oplus}$ Rapid Test for detection of carcinoma in situ for bladder cancer. Tumour Biol 2017;39:1010428317701624.

69. Chen YT, Chen CL, Chen HW, Chung T, Wu CC, Chen CD, et al. Discovery of novel bladder cancer biomarkers by comparative urine proteomics using iTRAQ technology. J Proteome Res 2010;9:5803-15.

70. Masuda N, Ogawa O, Park M, Liu AY, Goodison S, Dai Y, et al. Meta-analysis of a 10-plex urine-based biomarker assay for the detection of bladder cancer. Oncotarget 2018;9:7101-11.

71. Soukup V, Kalousová M, Capoun O, Sobotka R, Breyl Z, Pešl $\mathrm{M}$, et al. Panel of urinary diagnostic markers for non-invasive detection of primary and recurrent urothelial urinary bladder carcinoma. Urol Int 2015;95:56-64.

72. Shabayek MI, Sayed OM, Attaia HA, Awida HA, Abozeed H. 
Diagnostic evaluation of urinary angiogenin (ANG) and clusterin (CLU) as biomarker for bladder cancer. Pathol Oncol Res 2014;20:859-66.

73. Salomo K, Huebner D, Boehme MU, Herr A, Brabetz W, Heberling $\mathrm{U}$, et al. Urinary transcript quantitation of CK20 and IGF2 for the non-invasive bladder cancer detection. J Cancer Res Clin Oncol 2017;143:1757-69.

74. Snell KIE, Ward DG, Gordon NS, Goldsmith JC, Sutton AJ, Patel P, et al. Exploring the roles of urinary HAI-1, EpCAM \& EGFR in bladder cancer prognosis \& risk stratification. Oncotarget 2018;9:25244-53.

75. Yang Y, Xu J, Zhang Q. Detection of urinary survivin using a magnetic particles-based chemiluminescence immunoassay for the preliminary diagnosis of bladder cancer and renal cell carcinoma combined with LAPTM4B. Oncol Lett 2018;15:792333.

76. Santi R, Cai T, Nobili S, Galli IC, Amorosi A, Comperat E, et al. Snail immunohistochemical overexpression correlates to recurrence risk in non-muscle invasive bladder cancer: results from a longitudinal cohort study. Virchows Arch 2018;472:60513.

77. Azevedo R, Soares J, Gaiteiro C, Peixoto A, Lima L, Ferreira $D$, et al. Glycan affinity magnetic nanoplatforms for urinary glycobiomarkers discovery in bladder cancer. Talanta 2018;184:347-55.

78. Feldman AS, Banyard J, Wu CL, McDougal WS, Zetter BR. Cystatin B as a tissue and urinary biomarker of bladder cancer recurrence and disease progression. Clin Cancer Res 2009;15:1024-31.

79. Barboro P, Rubagotti A, Orecchia P, Spina B, Truini M, Repaci E, et al. Differential proteomic analysis of nuclear matrix in muscle-invasive bladder cancer: potential to improve diagnosis and prognosis. Cell Oncol 2008;30:13-26.

80. Moreira JM, Ohlsson G, Gromov P, Simon R, Sauter G, Celis JE, et al. Bladder cancer-associated protein, a potential prognostic biomarker in human bladder cancer. Mol Cell Proteomics 2010;9:161-77.

81. Orenes-Piñero E, Barderas R, Rico D, Casal JI, GonzalezPisano D, Navajo J, et al. Serum and tissue profiling in bladder cancer combining protein and tissue arrays. J Proteome Res 2010;9:164-73.

82. Chung H, Kim B, Jung SH, Won KJ, Jiang X, Lee CK, et al. Does phosphorylation of cofilin affect the progression of human bladder cancer? BMC Cancer 2013;13:45.

83. Grau L, Luque-Garcia JL, González-Peramato P, Theodorescu D, Palou J, Fernandez-Gomez JM, et al. A quantitative proteomic analysis uncovers the relevance of CUL3 in bladder cancer aggressiveness. PLoS One 2013;8:e53328.

84. Srinivasan H, Allory Y, Sill M, Vordos D, Alhamdani MS, Rad- vanyi F, et al. Prediction of recurrence of non muscle-invasive bladder cancer by means of a protein signature identified by antibody microarray analyses. Proteomics 2014;14:1333-42.

85. Hemdan T, Lindén M, Lind SB, Namuduri AV, Sjöstedt E, de Ståhl TD, et al. The prognostic value and therapeutic target role of stathmin-1 in urinary bladder cancer. Br J Cancer 2014;111:1180-7.

86. Chen CL, Chung T, Wu CC, Ng KF, Yu JS, Tsai CH, et al. Comparative tissue proteomics of microdissected specimens reveals novel candidate biomarkers of bladder cancer. Mol Cell Proteomics 2015;14:2466-78.

87. Wu TF, Li CF, Chien LH, Shen KH, Huang HY, Su CC, et al. Galectin-1 dysregulation independently predicts disease specific survival in bladder urothelial carcinoma. J Urol 2015;193:1002-8.

88. Bansal N, Gupta A, Sankhwar SN, Mahdi AA. Low- and highgrade bladder cancer appraisal via serum-based proteomics approach. Clin Chim Acta 2014;436:97-103.

89. Bansal N, Gupta AK, Gupta A, Sankhwar SN, Mahdi AA. Serum-based protein biomarkers of bladder cancer: a pre- and post-operative evaluation. J Pharm Biomed Anal 2016;124:225.

90. Lemańska-Perek A, Lis-Kuberka J, Lepczyński A, DratwaChałupnik A, Tupikowski K, Kątnik-Prastowska I, et al. Potential plasma biomarkers of bladder cancer identified by proteomic analysis: a pilot study. Adv Clin Exp Med 2019;28:33946.

91. Messana I, Cabras T, Iavarone F, Manconi B, Huang L, Martelli $\mathrm{C}$, et al. Chrono-proteomics of human saliva: variations of the salivary proteome during human development. J Proteome Res 2015;14:1666-77.

92. de Velasco G, Trilla-Fuertes L, Gamez-Pozo A, Urbanowicz M, Ruiz-Ares G, Sepúlveda JM, et al. Urothelial cancer proteomics provides both prognostic and functional information. Sci Rep 2017;7:15819.

93. Morera DS, Hasanali SL, Belew D, Ghosh S, Klaassen Z, Jordan $\mathrm{AR}$, et al. Clinical parameters outperform molecular subtypes for predicting outcome in bladder cancer: results from multiple cohorts, including TCGA. J Urol 2020;203:62-72.

94. Kollberg P, Chebil G, Eriksson P, Sjödahl G, Liedberg F. Molecular subtypes applied to a population-based modern cystectomy series do not predict cancer-specific survival. Urol Oncol 2019;37:791-9.

95. Timp W, Timp G. Beyond mass spectrometry, the next step in proteomics. Sci Adv 2020;6:eaax8978.

96. Callahan N, Tullman J, Kelman Z, Marino J. Strategies for development of a next-generation protein sequencing platform. Trends Biochem Sci 2020;45:76-89. 